been absorbed will be found in, or close to, the inner aspect of the wounds, whilst, in the latter, the virus, if injected into the areolar textures, may be squirted in all directions, and over a considerable area. Even in cases where a chap, or an open sore, has been licked by a rabid animal, excision is preferable to any other mode of prophylaxis.

Doubtless, excision should, whenever practicable, be performed as soon as possible. But there is reason to believe that, in exceptional cases, it may be successfully practised after cicatrisation of the wounds, or even thirty-one days after the bite, as in the case published by Rust, and cited by Sir William Gull. Seeing the early period at which symptoms may appear, such postponement of the excision should never receive the sanction of the responsible medical adviser. The experience, however, is encouraging, inasmuch as it is calculated to show, as far as a single instance can, that life may be saved by excision long after the wounds have cicatrised. Perhaps the extensive changes that have taken place meanwhile in the cicatrix, skin, and subjacent fat, to the extent of an inch around the site of the original wound, in the course of a few weeks, as demonstrated by Dr. Coats, would appear to indicate the necessity for a much larger removal of structure, under such circumstances, than would be at all required were it performed immediately after the bite, or before the wound had been healed up.

In conclusion, much hydrophobia may be prevented by (I) restricting the numbers of stray, pet, and domestic dogs and cats by $(a)$ police regulation and (b) licensing ; (2) by muzzling those which are known to be excessively pugnacious, or too ready to assume the offensive, with or without provocation ; (3) by careful and kindly attention to the sick and distempered; (4) by the extermination of such as become rabid.

\section{A CASE OF HYDROPHOBIA.}

By JAMES FOWLER, M.R.C.S. Eng.,

Surgeon to the Clayton Hospital and General Dispensary, Wakefield.

HYDROP lifetime without seeing a single case, I have thought it worth while to give the following notes of a well-marked one. I was indebted for the opportunity of seeing it to the kindness of Mr. Wiseman, under whose care the patient, a fine strongly built man of sixty-one years of age, was lying at Ossett, near Wakefield.

. L., a labourer, had always been a healthy man, never having required a doctor but once in his life, and then only for a broken finger. About two months before the first appearance of symptoms, he was putting some fresh straw into the kennel of a spaniel belonging to his master, when the dog, which had always been fond of him, and up to that time had seemed perfectly healthy, snapped at him and bit his left thumb. The same night the dog ran away, and has never been heard of since. The wound healed quickly, and the accident was soon forgotten. In the forenoon of Wednesday, May Igth, I880, however, having been apparently perfectly well up to that time, he felt a pain in his arm, which shot up to his shoulder, gradually increasing as the day went on, and seeming, by spreading over the chest, to cause a difficulty in breathing. There was no sickness or vomiting, nor disorder of the stomach; but at the same time he could take but little food, though usually he had a good appetite ; and he complained of being "starved to death", and all night was shivering and restless. Though the room was small, and there was but little air in it, he complained of incessant draughts, and called for extra curtains-saying they would "starve him to death and kill him"; just as patients with erysipelas complain of draughts, or the sensation of wind blowing over the face, etc., possibly from a hyperæsthesia of the skin, or disturbance of the circulation in it, or pyrexia. On Thursday morning, he found he had a difficulty in swallowing, in addition to the above symptoms; could eat but little breakfast, and felt depressed and out of sorts ; or, as he said, "not so well"; and yet he went at half-past five to attend to a greenhouse fire, and then to his work at seven, as usual. In the middle of the day, he could not eat his dinner; but went back to his work, and worked until six o'clock in the evening. On reaching home, he could at first only swallow a mouthful or two of tea, and that with the greatest difficulty; but, determined to finish the cup if possible, he made many trials, jumping up ten or a dozen times to walk across the floor, because, as he said, he could not breathe, and eventually took the whole, having at that time no terror of liquids. It was only now that anyone thought for the first time of sending for medical advice; and, when the doctor came at last, it was without the patient's consent. Mr. Wiseman found him complaining of great stiffness of the muscles of the throat and tongue; great difficulty in swallowing; difficulty of breathing, with twitching of the mouth; and extreme sensitiveness to the least breath of air. In the early part of the night, he told his wife to open the window, as he could not breathe; but soon told her to shut it, or "the cold air would kill" him. The night was again passed without sleep, in the greatest misery-part of the time being passed in pacing the floor of his room; he had no pain, he said, but could not "draw breath". On Friday morning, the difficulty of swallowing had increased so much that a fit of choking was induced by any attempt to drink, and after that time he was totally unable to swallow a drop. The saliva even could not be swallowed, but ran out of his mouth; his pharynx was apparently spasmodically contracted; and the breathing was very difficult, being frequently spasmodically arrested. There was almost constant twitching of the muscles of the mouth and limbs, which in creased as the day went on until the movements became convulsive and, to the previous inability to swallow liquid, was now added an extreme dread of it. Draughts of air in the room, or movements of any kind, brought on immediate spasms. Mr. Wiseman recognised the nature of the disease, and looked for and found the cicatrix on the thumb left by the bite two months ago. The patient again passed an extremely restless night, unable to stay in bed more than a minute or two at a time, continually getting up to walk about; but, on Saturday morning, slept comfortably for some time. At 3 P.M., I saw him with Mr. Wiseman. He was then sitting up in bed, in extreme agonising distress and terror, but unable to explain in what it consisted, though apparently quite conscious and rational; imploring, beseeching, by gesture and expression, for something, but unable to say what ; talkative, but only in short incoherent, jerky sentences, rapidly and wildly uttered, as by an insane person: "Lord have mercy on me", etc. ; and neither heeding nor answering questions, as though entirely absorbed in his own manifest distresses. If anyone approached him, he motioned with his arm for him to begone, and would say, repeatedly, "My good man, my good man, keep from front of me", being extremely intolerant of anyone passing between him and the window, even at a distance. If anyone moved in the room, or opened a door,"or even spoke, there were a violent spasm of the pharynx and inspiratory muscles, and distortion of the mouth, which came on at intervals, however, without any apparent cause-possibly a reflex phenomenon, produced by some sight or imagination of something which had previously distressed him, acting on a too extremely sensitive nervous centre; or by mucus or saliva collecting in the fauces, the throat not allowing the passage of even the natural saliva, which, however, was much increased in quantity, there being by the side of the bed half a large chamber utensil full of glairy saliva, which had been hawked or spat up since morning. Though saliva rapidly accumulated in his mouth, and he constantly made efforts to expel it, there was nothing that ignorance or credulity could well exaggerate into the foaming or barking of a dog ; nor did he ever make the least attempt to strike, or scratch, or bite anyone near him ; nor did any of those present and about him seem in the least to expect or fear anything of the kind. At times, when convulsed, he would throw himself completely out of bed, unless restrained, but without pain apparently in the contracted muscles; and sometimes he was perfectly still and free from spasm of any of the voluntary muscles, without any tension whatever of the spinal muscles, the muscles of the jaw especially being in constant motion-spitting or speaking; while, as a rule, when not convulsed or in spasm, he was extremely restless, mentally agitated, throw. ing his head, or arms, or legs about, and able to raise himself in bed or walk across the floor - the case, by these peculiarities, being strikingly distinguished from one of tetanus. The face was extremely anxious, pallid, pinched, perspiring; the eyes bright, restless, glancing continually apparently with either suspicion or terror; the tongue clammy, coated with thin white fur and viscid saliva; the bowels obstinately confined-not having been opened by an aperient administered at first whilst he was still able to swallow; the pulse very small, weak, and frequent. Some hours afterwards, the body began to be covered with large, dark, livid patches. At 9. IO P.M., on waking out of a short but comfortable sleep, he called his son upstairs, and seemed for the moment still quite conscious, and in his senses; he could not speak, however, and died almost immediately - rather suddenly at last, sitting up in bed as before, only three days and a half after first complaining, and after but two clays' absence from his daily labour.

As regards treatment, it only remains to be said that, practically, no treatment whatever was applied to the bite in the first instance, as the man never saw a doctor; he rubbed the wound with a "rubbing bottle" of "oils", went about for a few days with a rag tied round the finger " to keep the dirt out", and said he was " ne'er afraid of a dogbite". Afterwards, when Mr. Wiseman saw him, hypodermic injections of morphia were administered-on Friday morning a quarter of a grain, on Saturday morning half a grain-which seemed to have a decidedly calmative and beneficial effect, inducing snatches of peaceful and refreshing slumber. But exhaustion was already rapidly setting in when I saw the case ; and, though we tried to get up some enemata of strong 
beef-tea for nourishment, and of water to quench thirst, it was impossible, as he could never be made still enough to endure it; nor was it even possible to reassure him, or offer the slightest comfort or consolation, as he seemed unable to listen to anything, so entirely absorbed was he in his appalling suffering.

A careful post mortem examination was made by Mr. Wiseman 42 hours after death. The rigor mortis was very marked indeed, the body not arching at all when a block was placed beneath the abdomen, in order to place the body in a suitable position for the removal of the spinal cord. The blood was abnormally fluid. There was rather more obvious congestion of the corpse than usual, and of the central nervous organs; but without serous effusion. The lungs also were more decidedly congested, being dark purple in colour; but all other organs of the body were perfectly healthy.

\section{CASE OF HYDROPHOBIA ; RECOVERY. \\ B Y JOHN RUXTON, M.B. Surgeon Army Medical Department.}

P., a boy, aged between five and six years, was bitten at Peshawur, East Indies, on September 20th, 1874, by an infuriated bull-bitch, which was soon afterwards destroyed; and being chained at the time, ad no chance of doing further damage. The bites were very severe, and situated at the top of the right thigh externally and on the right eg; they were freely cauterised with fuming nitric acid within half an hour, which caused considerable loss of tissue; and were afterwards Jressed with carbolised oil ( $\mathrm{I}$ in 40 ) to promote granulation. The healing process went on satisfactorily, but he occasionally complained of itching and irritability of cicatrices on the thigh, frequently rubbing off the scab over the seat of the wound, where cicatricial loss of tissue was still apparent. There was no other symptom of constitutional disease.

On October 19th, 1874, almost a month from the date of being bitten by the bitch, his father remarked that the boy was very heavy and feverish, and sent him home to bed. Feeling no better on the 2oth, he was kept in bed, his skin being then very hot, and he was very thirsty, drinking lemonade freely. About 5 P.M. the same evening, his symptoms became more alarming, he being unconscious, taking no notice of his parents or others around him, and refusing food or drirk, dozing off to sleep, but disturbed by the slightest noise. The parents, thinking this a case of ague, sent for Mr. Offerman, the assistant apothecary then in charge, who prescribed some calomel and James's powder, and was packing the child in a cold sheet, according to my usual treatment, when a sudden convulsion supervened, again recurring in one and a half hours. The father, dreading some connection between the dog-bite and present symptoms, requested me to see the boy; this I at once did, and found him very feverish and restless, with beads of saliva about his mouth. I suspected the worst, but did not give any pronounced opinion to the parents, as it might have been ague with convulsions, which in earlier childhood present themselves in so many ways. I ordered the tepid sheet, and the child to he well covered with blankets, and gave a diaphoretic mixture; the case to be carefully watched, and any change of symptoms to be at once reported to me. Diaphoresis and sleep followed, which latter lasted till I A.M. on the morning of October 2 Ist, when he suddenly awoke in a screaming fit, as his mother expressed, "screaming wildly, not as if he were hurt". The father came for me at once; and on my arrival at his house, the poor lad had the most intense fits, screaming violently; he had clonic interrupted muscular contractions, twisting sometimes to the side, foaming at the mouth, spitting saliva from between the teeth, dreading all liquids, the slightest disturbance reproducing these frightful contortions. From the previous history, the anxiety manifested by the intelligent parents, and the characteristic symptoms, my diagnosis of hydrophobia was justified, I think; in which opinion Assistant-Apothecary Offerman unhesitatingly coincided. No other medical officer was with my regiment at the time; and the parents seemingly had implicit faith in me, for they said they did not wish another medical mar. Thinking nothing could be done, I did not insist.

I warned the parents for the worst; but, thinking he had some pain about the abdomen, and screaming as if suffering from worms, I ordered an enema of half an ounce of castor-oil and sixty minims of turpentine with soapsuds, but nothing of note came away. Perfect quietude was enjoined; and while pondering over the lad's wretched state, the happy and soothing effects of cannabis Indica I had previously experienced, and which are hereafter more fully t?etailed, flashed across my mind, and as a palliative I determined to try it. Five minims of the tincture were with great difficulty given by the mouth, and sleep for a short time followed; but he again awoke in a wild screaming fit, and spitting saliva from between his teeth. As there were several other children in the house, and a spare ward was made ready in hospital, I removed him thither, explaining to his parents that he would not be seen by other members of his family in this hopeless state, and that I did not expect he would live long. The room was darkened and isolated, most complete quietude rigidly enforced, and five minims of tincture of cannabis Indica were repeated by mouth in short convulsive gulps; most of it, however, was swallowed, I think. A deep sleep, lasting for ten hours, soon followed, and he awoke conscious of those around him, recognising his mother for the first time for twenty-seven hours. His pupils were contracted to a point; and, he seeming very heavy, went quickly to sleep again for another twelve hours, with slight interruptions till the morning of October 22nd, when, to my utter astonishment, he took some milk and beef-tea without difficulty, still seeming heavy and dozing off to sleep at intervals during the day. I determined to continue for one night more my physiological dose of cannabis Indica; and after careful feeding with beef-tea, I administered five minims by the mouth without difficulty about 5 P.M., which kept him asleep for eighteen hours, during which time he was carefully watched, his pulse and respirations more particularly, both of which continued good throughout ; and I now regret I did not tabulate them, but I had my hands full at the time.

When he awoke on the forenoon of October $23 \mathrm{rd}$, his pupils were very much ccntracted; he seemed drowsy, weak, and blanched, with languid circulation, but free from fits, and all the other frightful symptoms we had witnessed. I afterwarcis fed him well for a week on non-stimulating diet, and prescribed tonic doses of quinine and nitrohydrochloric acid, which in that aguish district did good in any convalescence ; and he was discharged, but to attend and see me occasionally.

On October 30 th, he was well and hearty, and seemingly none the worse for his recent attack and long sleep. I last saw him in 1878 , when I left my regiment; he was then in good health, the cicatrices alone remaining.

REMIARKS.-Judging from the result, some may be sceptical about my diagnosis. I can only remark I had no cioubt of it when I removed the child to hospital, as I thought, to die ; it seems too good also to be true ; but why change my diagnosis because he recovered? I hoped ere now to have had further opportunity of trying my vaunted remedy, but have not; and would have wished to give a more definite rationale of treatment. I, however, state facts, and leave to mere fertile brains and abler pens to supply the theory; but I hope some of the readers of the JOURNAL may give it a trial, and that I may yet hear of cures of hydrophobia by physiological and repeated doses of cannabis Indica.

Reverting to my original idea of giving cannabis Indica, I recalled to memory the vivid description given us by our learned and highly respected Professor of Materia Medica in the University of Aberdeen where I studied-Alexander Harvey-more especially about the smoker dreaming he was climbing hills of Cavendish tobacco, which, to an indulger in that so-called pernicious plant, was too great a temptation for frail mortal, and I determined to taste the pleasures of Indian hemp; and I now relate my experience. On dismissal of the class, I took a fair dose, was highly exhilarated thereby, and, to use a vulgarism, had very jolly sensations all over, content with my temporary paradise; then, feeling heavy and drowsy, I sat down on the window-sill of a fashionable shop, and was asleep in a short time, as I was afterwards told by two fellow-students, in a stage of intoxication, which the passers-by, in their usually charitable spirit to medical students, no doubt attributed to alcohol. My two friends, who had been watching me throughout, had considerable sport at my expense, but did not leave me till I awoke from a sound and refreshing sleep. My object in this case being to make this wretched lad happy, though only as a palliative, I tried my old friend cannabis Indica, and with the best results. The drur was given by the mouth with difficulty, and I wondered he swallowed as much as he did; had I failed to give the medicine in this way, the hypodermic method could be used. The natives of India smoke it as "bang"; they say it makes them happy, relieves indigestion, and gives a glowing sensation all over.

In conclusion, I gave the first close as a palliative, aiming at giving the lad rest and ease. Finding it partially successful, I was encouraged to give a second dose, which exceeded my most sanguine expectations; and profiting by a case of locked jaw about which I then read, which was relieved by Calabar bean, so long as the remedy was given, while on its withdrawal the disease recurred, I determined to continuc for one night more, and carefully watch the case.

Medicai. Magistrates. - Dr. Wilberforce Arnold, and Dr. Dempsey, have been appointed to the Commission of the Peace for the borough of Belfast. 